\title{
Using Odorant Series as an Analytical Tool for the Study of the Biological Ageing of Sherry Wines
}

\author{
Luis Zea, María J. Ruiz and Lourdes Moyano \\ University of Córdoba/Department of Agricultural Chemistry, \\ Spain
}

\section{Introduction}

By using analytical techniques, the number of characterised compounds in white wine has been increased to more than 800 (Etievant, 1991; Bayonove et al., 2000). However, only a limited number of them have any significance in the determination of flavour. A method is therefore needed in order to measure the aromatic potency of the different volatile compounds so as to distinguish those compounds which contribute significantly to the overall aroma of wine. With this in mind, several authors (Guth, 1997; Audoin et al., 2001; Aznar et al., 2001; Moyano et al., 2002; Lopez et al., 2003; Rocha et al., 2004; Moreno et al., 2005; Chaves et al., 2007; Zea et al., 2007, 2008; Moyano et al., 2009, 2010; Ruiz et al., 2010; Zea et al., 2010) propose an estimation of the importance of a flavour compound on the basis of its Odour Activity Values (OAVs). Using the calculated OAVs and odour descriptors, we study the odour profile of sherry wines in order to identify differences in the typical aroma compounds ascribable to the ageing procedure used (whether biological or oxidative). However, the large number of compounds involved in the aroma fraction of wine, and the differential odour impact of each one, makes any conclusions difficult and speculative. As such, the aroma fraction of sherry wines was studied by grouping into odorant series (OSs) the odour activity values of the compounds exhibiting similar odour descriptions. This method has the advantage that it greatly reduces the number of variables to be interpreted, preserving their relative importance according to the OAV of each compound. The OS, as an analytical tool, allows the comparison of the aroma fractions of Fino wines with different ageing times so as to study the changes in the aromatic fingerprints during the ageing stage of wines.

\section{Sherry wines}

The well-known sherry wines are principally produced in two southern regions of Spain, Jerez and Montilla-Moriles. The climate of these regions largely determines the typical composition of these wines and includes moderately low average minimum temperatures (lows of $5{ }^{\circ} \mathrm{C}$ in winter and highs of $17^{\circ} \mathrm{C}$ in summer) and high temperatures in the summer (above $35^{\circ} \mathrm{C}$ or even above $40^{\circ} \mathrm{C}$ during the grape-ripening stage). The region is a dry zone, where rainfall is unevenly distributed throughout the year and at times is around $400 \mathrm{~mm}$ 
below average. These favourable climatic conditions allow the white grape varieties used to obtain sherry wines (Palomino Fino and Pedro Ximenez) to reach a high reducing sugar concentration, above $250 \mathrm{~g} \mathrm{~L}^{-1}$ in some areas. Due to this, fortification is not necessary after the alcoholic fermentation of the base wine since it has a high ethanol content, of about $15 \%$ $(\mathrm{v} / \mathrm{v})$, which is obtained in a natural manner. The musts have a low acidity $\left(3-4.5 \mathrm{~g} \mathrm{~L}^{-1}\right.$ as tartaric acid) which is generally increased by the winemakers. Moreover, the musts are added to $\mathrm{SO}_{2}$ concentration of around $100 \mathrm{mg} \mathrm{L}^{-1}$.

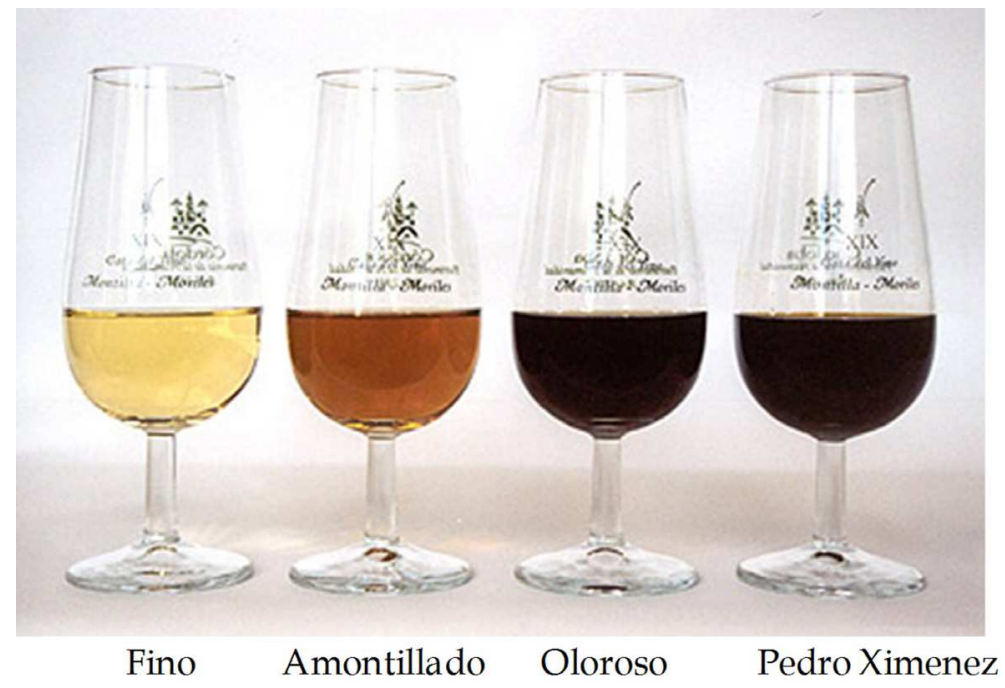

Fig. 1. Sherry-type wines: Fino, Amontillado, Oloroso and Pedro Ximénez

Following harvesting, the grapes are stemmed and pressed. Plate presses are most widely used for this purpose, even though pneumatic ones are more efficient (as they apply pressure in a more uniform manner). The must obtained from the first pressing - called "yema" - and that obtained in subsequent ones, is centrifuged or racked to remove suspended solids. It is then pumped into stainless steel containers or concrete cones and allowed to ferment. During the process, special care is exercised to prevent the temperature from rising above $25-26^{\circ} \mathrm{C}$. The refrigeration systems currently available can efficiently maintain even lower temperatures.

So-called Fino, Amontillado and Oloroso wines (Figure 1) are three typical types of dry sherry wines obtained under identical fermentation conditions (with same wine base) but with different ageing conditions and procedures as part of the "criaderas" and "solera" system. A more detailed description of this system can be found in the next section. Thus, while Fino wines are aged exclusively by biological ageing, Oloroso wines are obtained by chemical ageing only. However, Amontillado wine is aged by involving both methods sequentially, so that the wine initially undergoes biological ageing - as with a Fino wine - 
and then chemical ageing, like an Oloroso wine. The first type of sherry wine has a very light yellow colour, with an almond flavour and pungent notes, while the second type has a very dark colour that results from the oxidation of phenolic compounds, and a flavour with distinct notes of oak and walnut. Finally, the third type of sherry wine has a colour in between the two previous wines, but closer to the Oloroso wine, and it has a flavour with hazelnut notes that is the most complex among the three (Medina et al., 2003).

A special sherry is the famous Pedro Ximenez sweet wine (Figure 1) which is produced from raising grapes containing more than $400 \mathrm{~g} \mathrm{~L}^{-1}$ of sugars. The musts obtained are fortified to an ethanol content of $13.5 \%(\mathrm{v} / \mathrm{v})$ and are afterwards subjected to oxidative ageing in a "criaderas" and "solera" system.

\subsection{The "Criaderas" and "Solera" ageing system}

Essentially, this industrial ageing method involves storing the wine in $500 \mathrm{~L}$ American oak casks, which are stacked in rows called "escalas". The casks in each "escala" contain wine of the same degree of ageing. The first "escala" - called the "solera" - is that closest to the ground and it contains the oldest wine. A fraction of its volume is withdrawn periodically for bottling. After each withdrawal, the casks of the "solera" are replenished with wine from the second "escala" - also called the first "criadera" - which in turn is replenished with wine from the third "escala" (the second "criadera") and so forth. The topmost "escala" - called the "añada" - contains young wine from the year's vintage. More detailed information about this traditional ageing method can be found in the papers by Casas (1985), Domecq (1989), and Zea et al. (1996, 2008).

\section{The biological ageing of sherry wines}

The production of Fino type sherry wine involves a long biological ageing process (5-7 years) that is carried out by "flor" yeasts. More than $95 \%$ of these yeasts are identified as Saccharomyces cerevisiae races (Martinez et al., 1997). These microorganisms grow spontaneously on the wine surface after the alcoholic fermentation of the must and develop an aerobic metabolism that endows the resulting product with typical sensory properties as regards the aroma (Cortes et al., 1998; Moyano et al., 2002; Moreno et al., 2005). The biosynthesis of acetaldehyde and the consumption of ethanol, glycerine and volatile acids by the "flor" yeasts are the most typical and best known reactions which take place in wine during biological ageing. Acetaldehyde is synthesised by means of the enzyme alcohol dehydrogenase in the presence of $\mathrm{NAD}^{+}$(Garcia-Maiquez, 1988). According to Zea et al. (2001), the acetaldehyde content allows the differentiation of Fino wines from other types of sherry wines produced by oxidative ageing. Acetaldehyde is responsible for the pungent character typical of Fino wine and it directly contributes to the ethereal and ripe apple notes of its aroma. Likewise, this compound is a precursor for the synthesis of other odorant products, thereby indirectly contributing to several distinctive notes to the aroma profile of wine. "Flor" yeast also increases the contents of other aroma compounds such as higher alcohols and acetates, ethyl esters, lactones and terpenes (Zea et al., 1995). Consequently, the aroma composition of the biologically aged wine is rather different of young wine (Moyano et al., 2002). 
To facilitate the ageing of the wine, cellars must be conditioned to maintain a constant temperature of $15-18{ }^{\circ} \mathrm{C}$, with a relative humidity as high as possible and efficient ventilation throughout the year. This procedure provides the wine with similar sensory properties year after year and allows the yeasts to be brought into contact with younger wines, which supply the nutrients required for the "flor" (yeast film) to develop and grow and thereby ensure the desired homogeneity and inalterability in the ageing of the Fino wines. In addition, "flor" yeasts protect the wine from chemical browning, preserving its pale colour throughout the ageing period (Baron et al., 1997). Moreover, the compound released by the wood of the casks and used in the ageing is the second most important way of contributing to the aroma of the wine. The type of wood, in addition to the ethanol content of the wine and the temperature of the cellar, are the main factors that influence the efficiency of extraction of such compounds (Singleton, 1995; Arapitsas et al., 2004). As a result, the Fino type is a dry white wine and is considered to be the world's finest sherry.

\section{The sherry aroma wheel}

With improved analytical methods there has been a large increase in the number of compounds identified in wines. Volatile compounds from different families (such as alcohols, esters, aldehydes, terpenes, etc.) play an important role in the organoleptic characteristics of wines. This wide variety of compounds with different chemical properties and with different concentrations makes the flavour profile of wines very complex. Therefore, it is necessary to standardise the terminology so as to facilitate the knowledge of the aromatic profile of wines.

In an article by Noble et al. (1984), the authors proposed an aroma wheel to standardise the terminology of the aromas of wines and so facilitate the communication among the members of the wine industry. The "Wine Aroma Wheel" provides a graphical representation of the different categories and aromatic components that can be found in the wine. Subsequently, a modified version of the wine aroma wheel (Noble et al., 1987) was constructed in order to clarify and improve the proposed list of standardised terminology. This version has been widely used to describe the flavour profiles of many types of wines in the world. However, many of the descriptive terms for wines on the wheel are not characteristic of sherry wines, for which some are not even listed. For this reason, it is necessary to define a wheel for sherry wines due to the characteristic flavour profile that they present. As far as we are aware, no aroma wheel has been developed for sherry wines.

The aim of this section is, therefore, to demonstrate a "Sherry Aroma Wheel" (Figure 2) in order to standardise the terminology for the aromatic description of these types of wines.

As can be seen, at the centre of the wheel are the eight odorant series (OSs) which group the odorant terms that define the flavour profile of these wines: fruity, chemical, empyreumatic, spicy, floral, vegetal, balsamic and fatty. By reading outwards first, from the odorant terms to the odour descriptors, a more precise description of the sherry aroma can be offered. 


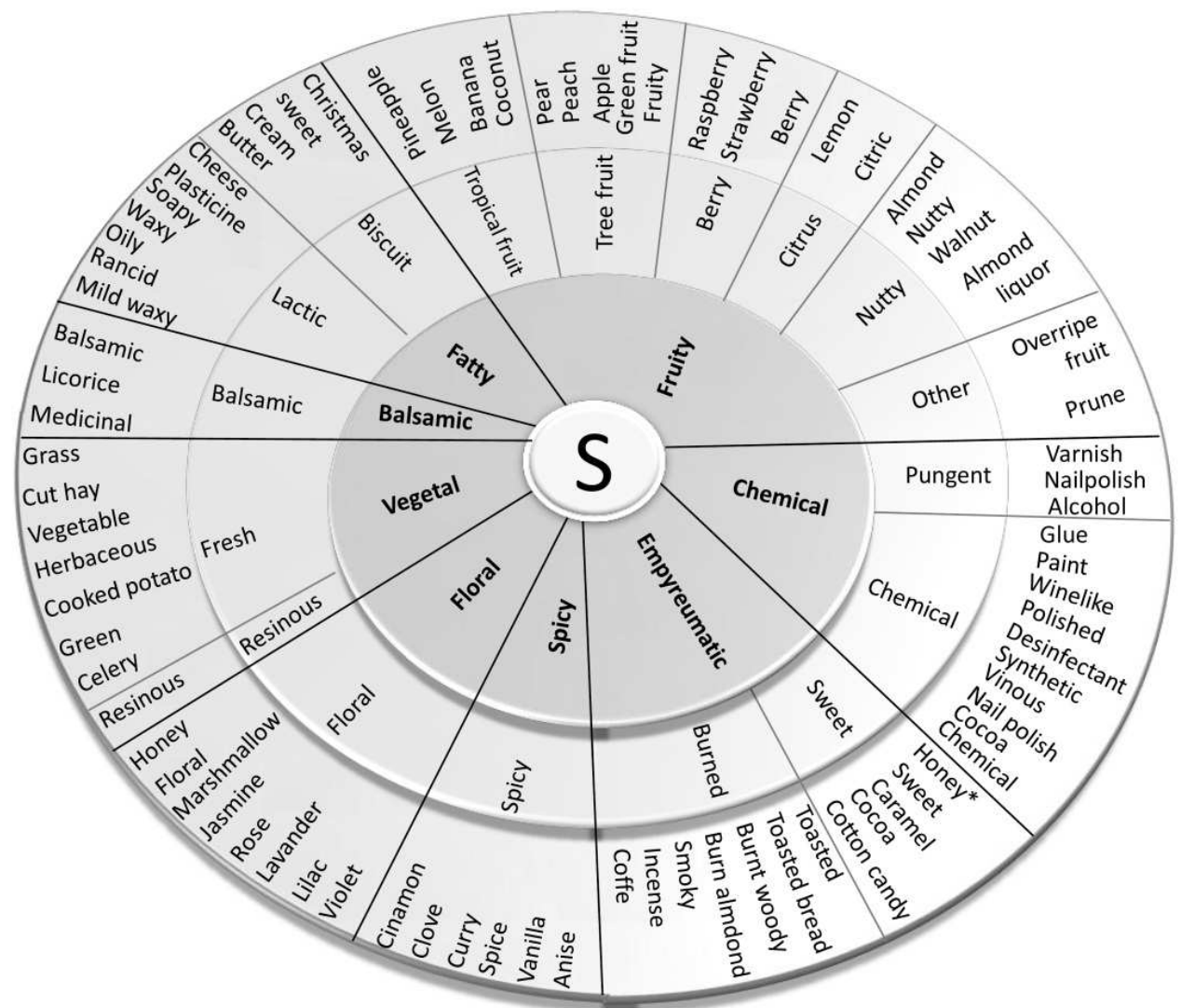

Moyano, L., Ruiz, M.J. \& Zea, L., 2011 ()

Fig. 2. Sherry Aroma Wheel showing the odorant series (OSs), odorant terms and odour descriptors

\section{Sherry wines studied}

Very pale sherry wines, (Fino-types) obtained from the grape cultivar Pedro Ximenez which were subjected to biological ageing in aerobic conditions in American oak casks were used. Because the concept of "vintage" is not applicable to sherry wines, for better precision the ageing times were calculated following commercial criteria (by considering the age and volume of the mixed wines in the "solera" and "criaderas" system), resulting in times of 0 (without ageing), 1.5, 2.5, 4.5 and 6 years (named "solera") under veil yeasts. These last samples are commercially considered to be high quality typical Fino sherry-type wines. Three different samples for each ageing time were used, and each sample was obtained by mixing the wine extract from 20 casks. Also, the samples were selected by expert tasters as being more representative among the wines produced in 21 cellars from the Montilla-Moriles region. 


\section{Aroma compounds analysis}

\subsection{The identification and quantification of aroma compounds}

Each of the aromatic compounds analysed was identified by means of its retention time, coeluted with a standard solution of the commercial product and confirmed by mass spectrometry (Hewlett-Packard 5972 MSD, Palo Alto, CA, USA). Positive ion electron impact mass spectra were acquired in scan mode, with a range of $\mathrm{m} / \mathrm{z} 39-300$ and a scan-rate of 1.6 scan s-1. For each compound the mass spectra was confirmed by comparison with the Wiley mass spectral library. The chromatographic column, injector and oven temperatures, carrier gas and its flow, were the same as those used for the quantification, as described below.

The volatile compounds were quantified by capillary column gas chromatography after continuous extraction of $100 \mathrm{~mL}$ of a wine sample with $100 \mathrm{~mL}$ of freon-11 for $24 \mathrm{~h}$. Previously, the wine was adjusted to $\mathrm{pH} 3.5$ and $5 \mathrm{~mL}$ of internal standard (30 mg L-1 of 2octanol) was added. The freon extract containing the volatile compounds was concentrated to $0.2 \mathrm{~mL}$ in a Kuderna-Danish microconcentrator and $3 \mu \mathrm{L}$ was injected into a HewlettPackard-5890 series II gas chromatograph equipped with an HP-INNOWax fused silica capillary column (60 $\mathrm{m} \times 0.32 \mathrm{~mm}$ ID, $0.25 \mu \mathrm{m}$ film thickness), with a FID and a sniffing port connected by a flow-splitter to the column exit. The oven temperature programme was as follows: $5 \mathrm{~min}$ at $45^{\circ} \mathrm{C}, 1^{\circ} \mathrm{C} \mathrm{min}-1$ ramp to $185^{\circ} \mathrm{C}$ and $30 \mathrm{~min}$ at $185^{\circ} \mathrm{C}$. The injector and detector temperatures were $275^{\circ} \mathrm{C}$ and $300{ }^{\circ} \mathrm{C}$, respectively. The carrier gas was helium at 70 $\mathrm{kP}$ and split 1:30. The quantification was made using chromatographic response factors, calculated for each compound in relation to the internal standard in standard solutions of commercial products supplied by Sigma-Aldrich (Munich, Germany). The acetaldehyde was quantified by using the enzymatic test from R-Biopharm (Darmstadt, Germany).

\subsection{Threshold, odour description and odorant series}

Although the odour descriptions and thresholds of the compounds can be obtained from previous research and bibliographic sources (Singleton, 1995; Kotseridis \& Baumes, 2000; Lambrechts \& Pretorius, 2000; Aznar et al., 2001; Lopez et al., 2003), the high content of ethanol in the studied wines advised their determination by a taste panel. The taste panel consisted of 20 judges of both sexes (between 20 and 55 years old), trained but not selected. The threshold is defined as the lowest concentration capable of producing a sensation. This sensation must be detected by at least $50 \%$ of the judges in a taste panel. Five solutions of ascending concentration of each compound (supplied by Sigma Aldrich, Germany) were used. Starting from the solution with the lowest concentration, the judges indicated an odorant sensation different to that perceived by the control $(14 \% \mathrm{v} / \mathrm{v}$ ethanol/water $)$. Likewise, the judges were asked for the aroma descriptors, and these were fixed by comparing with bibliography. The non-descriptive or abstract terms were eliminated. The coincident (or not very dissimilar) terms provided by at least $50 \%$ of the judges were considered to be similar and grouped in the eight OSs. The series used in this work grouped compounds with similar odour descriptors and represented the main constituents of the aroma profile of the Fino wine: fruity, chemical, balsamic, vegetal, fatty, empyreumatic, floral and spicy odours. Because of the high complexity of olfactory perceptions, some aroma compounds were included in two or more OSs, according to the findings of certain authors (Charles et al., 2000; Cliff et al., 2002; Rocha et al., 2004). Table 1 shows the odour descriptions, OSs and thresholds of the aroma compounds studied. 
Using Odorant Series as an Analytical Tool for

\begin{tabular}{|c|c|c|c|}
\hline Compound & Odour description & $\begin{array}{l}\text { Odorant } \\
\operatorname{series}\left({ }^{*}\right)\end{array}$ & $\begin{array}{l}\text { Threshold } \\
\left(\mathrm{mgL}^{-1}\right)\end{array}$ \\
\hline Acetaldehyde & overripe apple & 1 & 10 \\
\hline Ethyl acetate & pineapple, varnish, balsamic & $1,2,3$ & 7.5 \\
\hline 1,1-Diethoxyethane & green fruit, liquorice & 1,3 & 1 \\
\hline Methanol & chemical, medicinal & 2,3 & 668 \\
\hline Ethyl propanoate & banana, apple & 1 & 5 \\
\hline Ethyl isobutanoate & strawberry, melon & 1 & 0.015 \\
\hline Propyl acetate & glue, celery, Christmas sweet & $2,4,5$ & 65 \\
\hline 2,3-Butanedione & butter & 5 & 0.1 \\
\hline Methyl butanoate & strawberry, glue, cheese & $1,2,5$ & 1 \\
\hline Isobutyl acetate & apple, banana & 1 & 6.14 \\
\hline 2-Butanol & vinous & 2 & 1000 \\
\hline 1-Propanol & ripe fruit, alcohol & 1,2 & 830 \\
\hline Ethyl butanoate & banana, pineapple, strawberry & 1 & 0.020 \\
\hline Butyl acetate & banana, ripe pear, glue & 1,2 & 4.6 \\
\hline Isobutanol & alcohol, wine like, nail polish & 2 & 40 \\
\hline Isoamyl acetate & banana & 1 & 0.030 \\
\hline 1-Butanol & medicinal & 3 & 820 \\
\hline Isoamyl alcohols & alcohol, nail polish & 2 & 65 \\
\hline Ethyl hexanoate & banana, green apple & 1 & 0.005 \\
\hline 1-Pentanol & bitter almond, synthetic, balsamic & $1,2,3$ & 676 \\
\hline$p$-Cymene & citric, solvent, synthetic & 1,2 & 66 \\
\hline Ethyl pyruvate & vegetable, caramel & 4,6 & 100 \\
\hline Acetoin & buttery, cream & 5 & 30 \\
\hline Octanal & green, honey, soapy & $4,5,7$ & 0.64 \\
\hline 4-Methyl-1-pentanol & almond, toasted & 1,6 & 50 \\
\hline 3-Methyl-1-pentanol & vinous, herbaceous, cocoa & $2,4,6$ & 50 \\
\hline Ethyl lactate & strawberry, raspberry, buttery & 1,5 & 100 \\
\hline 1-Hexanol & grass, resinous, cream & 4,5 & 8 \\
\hline 3-Ethoxy-1-propanol & overripe pear & 1 & 50 \\
\hline Z-3-hexenol & grass, green & 4 & 100 \\
\hline Ethyl octanoate & pineapple, pear, soapy & 1,5 & 0.002 \\
\hline 1-Heptanol & oily & 5 & 2.5 \\
\hline Isobutyl lactate & banana, pear, balsamic, vegetal & $1,3,4$ & 340 \\
\hline Furfural & burn almond, incense, floral & 6,7 & 15 \\
\hline Ethyl 3-hydroxybutanoate & grape, marshmallow & 1,7 & 67 \\
\hline Benzaldehyde & bitter almond, nutty, smoky & 1,6 & 5 \\
\hline 1-Octanol & varnish, soapy, waxy, jasmine, rose & $2,5,7$ & 10 \\
\hline 5-Methylfurfural & bitter almond, spice & 1,8 & 16 \\
\hline Isobutanoic acid & rancid butter & 5 & 20 \\
\hline$\gamma$-Butyrolactone & coconut, caramel & 1,6 & 100 \\
\hline Butanoic acid & rancid, cheese & 5 & 10 \\
\hline Furfuryl alcohol & medicinal & 3 & 15 \\
\hline 3-Methylbutanoic acid & parmesan cheese, rancid & 5 & 3 \\
\hline 2,3-Butanediol & buttery, creamy & 5 & 668 \\
\hline Diethyl succinate & overripe, lavender & 1,7 & 100 \\
\hline Neral & lemon, citric & 1 & 1 \\
\hline Ethyl 3-hydroxyhexanoate & rubber & 3 & 0.045 \\
\hline a-Terpineol & lilac & 7 & 38 \\
\hline Methionol & cooked potato, cut hay & 4 & 0.5 \\
\hline
\end{tabular}

$\left.{ }^{*}\right) 1=$ fruity, $2=$ chemical, $3=$ balsamic, $4=$ vegetal, $5=$ fatty, $6=$ empyreumatic, $7=$ floral, $8=$ spicy

Table 1. Odour descriptions, odorant series and threshold of the aroma compounds in sherry-type wines. 


\begin{tabular}{|c|c|c|c|}
\hline Compound & Odour description & $\begin{array}{l}\text { Odorant } \\
\operatorname{series}(*)\end{array}$ & $\begin{array}{c}\text { Threshold } \\
\left(\mathrm{mg} \mathrm{L}^{-1}\right)\end{array}$ \\
\hline 1-Decanol & pear, polished, waxy, violet & $1,2,5,7$ & 5 \\
\hline$\beta$-Citronellol & rose & 7 & 0.1 \\
\hline Phenethyl acetate & rose, honey & 7 & 0.25 \\
\hline Hexanoic acid & cheese & 5 & 3 \\
\hline Benzyl alcohol & disinfectant & 2 & 900 \\
\hline E-Oak lactone & coconut, burn woody, vanilla & $1,6,8$ & 0.122 \\
\hline Phenethyl alcohol & rose, honey & 7 & 10 \\
\hline Z-Oak lactone & coconut, burn woody, vanilla & $1,6,8$ & 0.035 \\
\hline Pantolactone & liquorice, toasted bread & 3,6 & 500 \\
\hline 4-Ethylguaiacol & toasted bread, smoky, clove & 6,8 & 0.046 \\
\hline Diethyl malate & overripe peach, prune & 1 & 760 \\
\hline Z-Nerolidol & apple, vegetal, waxy, rose & $1,4,5,7$ & 64 \\
\hline Ethyl myristate & mild waxy, soapy & 5 & 494 \\
\hline Octanoic acid & rancid oily & 5 & 8.8 \\
\hline$\gamma$-Decalactone & peach & 1 & 1 \\
\hline Eugenol & cinnamon, clove & 8 & 0.005 \\
\hline 4-Ethylphenol & disinfectant & 2 & 140 \\
\hline Decanoic acid & rancid, waxy & 5 & 15 \\
\hline Phenethyl octanoate & synthetic, waxy, rose & $2,5,7$ & 10 \\
\hline Monoethyl succinate & caramel, coffee & 6 & 1000 \\
\hline Lauric acid & waxy, soapy & 2,5 & 10 \\
\hline Sotolon & walnut, cotton candy, curry & $1,6,8$ & 0.005 \\
\hline Ethyl furoate & glue, paint & 2 & 1 \\
\hline
\end{tabular}

(*) 1= fruity, 2= chemical, 3= balsamic, 4= vegetal, 5= fatty, 6= empyreumatic, $7=$ floral, $8=$ spicy

Table 1. (continued). Odour descriptions, odorant series and threshold of the aroma compounds in sherry type wines.

\subsection{Statistical procedures}

The OAVs and the basic statistics of the OSs were presented as the mean \pm SD of three samples for each ageing time. ANOVA and linear regression analysis were performed on the triplicated samples by using the Statgraphics 5.0 computer program (STSC Inc., Rockville, MD, USA).

\section{Odorant series as analytical tool in sherry-type wines}

The OSs used as an analytical tool for the study of Fino wines have already been defined in Table 1 and were calculated by adding the OAVs of all the corresponding compounds (including those with OAVs $<1$ ). From a theoretical point of view, these compounds did not directly contribute to the aroma profile, although some authors consider that these compounds may enhance some aromatic notes due to their synergistic effects with other odorant compounds (Freitas et al., 1999; Lopez et al., 1999).

It should be noted that the values obtained in the OSs do not necessarily represent arithmetic sums of the aroma perceptions. However, this method largely facilitates the comparison of the aroma profiles of wines of the same type, because the OSs used always included the same compounds. 
The aroma compounds studied during the biological ageing of Fino wines belong to different chemical families. The higher alcohols determined were methanol, 2-butanol, 1propanol, isobutanol, 1-butanol, isoamyl alcohols, 1-pentanol, 3- and 4-methyl-1-pentanol, 1hexanol, 3-ethoxy-1-propanol, Z-3-hexenol, 1-heptanol, 1-octanol, furfuryl alcohol, 2, 3butanediol, 1-decanol, benzyl alcohol and phenethyl alcohol.

Esters constituted the largest family and included acetates (ethyl, propyl, isobutyl, butyl, isoamyl, and phenethyl), ethyl esters of fatty acids (propanoate, isobutanoate, butanoate, hexanoate, octanoate, 3-hydroxybutanoate, 3-hydroxyhexanoate and furoate), ethyl esters of organic acids (pyruvate, lactate, ethyl myristate, diethyl malate and, mono- and diethyl succinate) and various other esters, such as methyl butanoate, isobutyl lactate and phenylethyl octanoate. The acids quantified included isobutanoic, butanoic, hexanoic, octanoic, decanoic, lauric and 3-methylbutanoic. The lactones included $\gamma$-butyrolactone, pantolactone, $\gamma$-decalactone and $E$ - and $Z$-oak lactone; and the terpenes included neral $\dot{\alpha}$ terpineol, $\beta$-citronellol and Z-nerolidol. The aldehyde family comprised acetaldehyde, benzaldehyde, furfural, 5-methylfurfural and octanal, and the phenol family included eugenol, 4-ethylphenol and 4-ethylguaiacol. Finally, 1, 1-diethoxyethane, acetoin, sotolon, 2, 3-butanedione, $p$-cymene and methionol were also determined.

The next four sub-sections show the different ways of using the OSs as analytical tools for the study of the biological ageing of sherry wines.

\subsection{Using the odorant series to estimate the degree of biological ageing of sherry wines}

In this section, we study changes in the OSs during the biological ageing of Fino sherry-type wines. Likewise, those OSs exhibiting a high correlation with the ageing time could be used as indicators for the degree of ageing of this type of wine.

As can be seen in Figure 3, all of the series showed OAVs $>1$ during the ageing process with the exception of the vegetal at 1.5 years. In addition, the OAVs for the eight series were higher after 6 years of ageing than at the beginning, providing evidence of an enrichment of the wine aroma. However, the floral OAVs, for the whole period studied, and the chemical OAVs, after 2.5 years, remained relatively constant, suggesting that these aroma series are unrelated to the biological ageing process. The major series throughout the process was fruity, with a maximum average OAV of 421 at 6 years of biological ageing $(51.6 \%$ of the total aroma). The fatty and spicy series, with OAVs of 163 and 130 respectively, accounted for $20.0 \%$ and $15.9 \%$ of the total wine aroma at the end of the ageing process. The remaining series studied showed OAVs below 50 and, as a whole, accounted for only $12.5 \%$ of the aroma profile of the final aged wine.

By examining the changes of the OSs during the ageing period, one can identify those that are most closely related to the process and that can thus be reasonably used as aroma indicators for the degree of ageing of Fino wines. With this purpose in mind, some simple regression models were applied to the OAVs for the series at different ageing times. In most cases, the differences among the correlation coefficients were too small to justify a clear selection for a specific model. From a practical point of view, the linear regression model was chosen because interpretation is more intuitive and simple. The results thus obtained are shown in Table 2. Nevertheless, the chemical, balsamic, and floral series exhibited 

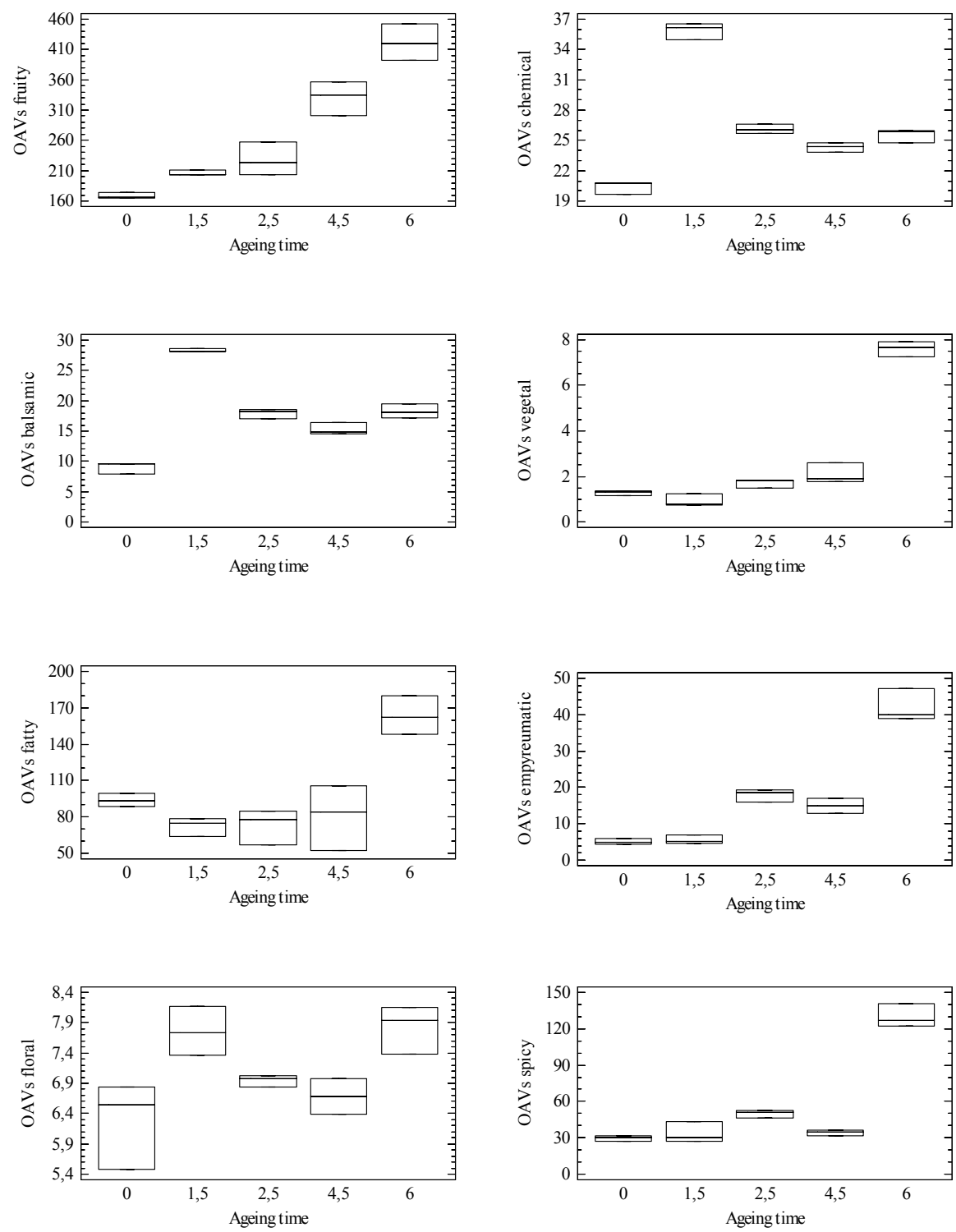

Fig. 3. Odour activity values (OAVs) of the odorant series (OSs) in sherry-type wines during their biological ageing.

$p>0.05$, so their fittings to a linear regression were not calculated. As can be seen, the OAVs for the fruity, empyreumatic and vegetal series exhibited very high significance $(p<0.001)$, corresponding to a high $\mathrm{R}^{2}$, particularly for the fruity series (0.9278). Based on the slopes of the regression lines obtained, the production-rate of compounds in the fruity series was much higher than those for the vegetal and empyreumatic series. This suggests that changes 
in the fruity series are highly dependent upon the biological ageing process. Taking into account that the most of the contributors to this series are related with the "flor" yeasts activity, the fruity OAVs can be used as an objective indicator of the contribution of these microorganisms to the process.

\begin{tabular}{|l|l|l|l|}
\hline Series & $\mathbf{p}$ & R-squared & slope \\
\hline Fruity & 0.0000 & 0.9278 & 42.5 \\
\hline Chemical & 0.9093 & nc & nc \\
\hline Balsamic & 0.6675 & nc & nc \\
\hline Vegetal & 0.0003 & 0.6421 & 0.935 \\
\hline Fatty & 0.0190 & 0.3556 & 10.2 \\
\hline Empyreumatic & 0.0000 & 0.7399 & 5.47 \\
\hline Floral & 0.1231 & nc & nc \\
\hline Spicy & 0.0013 & 0.5617 & 13.4 \\
\hline
\end{tabular}

nc: not calculated for the series with $p>0.05$

Table 2. Linear regression analysis of the OAVs of the series versus time in sherry-type wines during their biological ageing

\subsection{Use of odorant series to shorten the biological ageing of sherry wines}

In this study, commercial Fino sherry wines (5 years of biological ageing) which were selected by expert tasters as more representative were used. Also, selected strains of $S$. cerevisiae and S. bayanus (Kurtzman \& Fell, 1998) were used. These yeast strains, corresponding to the $\mathrm{S}$. cerevisiae capensis and bayanus races in the Kreger-van Rij classification (1984), were isolated from a velum of industrial wine produced in the Montilla-Moriles region. The criteria and tests for their selection have been reported in previous papers (Guijo et al., 1986; Moreno et al., 1991).

Figure 4a provides a plot of the values obtained for the OSs of the commercial wines studied. The figure shows the mean value for each series and those calculated, taking into account the standard deviations. In this mode, any value included between the highest and lowest in each series would be acceptable for a typical Fino wine. As can be seen, the fruity, balsamic, chemical and spicy series were those that contributed most markedly to the aroma profile.

To examine the utility of the analytical profile based in OSs, two experiments on the potential acceleration of the biological ageing of sherry wine were carried out. For their development, selected strains of S. cerevisiae and S. bayanus (two typical "flor" yeasts) were inoculated on un-aged wine contained in glass vessels, it being maintained at a constant temperature of $20{ }^{\circ} \mathrm{C}$ for 9 months. Figure $4 \mathrm{~b}$ shows the OSs of the wines aged with two "flor" yeasts, determined in the same way as for the above-mentioned commercial wines. For the better clarity of the results obtained, this figure only shows the mean value for each aroma series, and those that resulted in significant differences at $p<0.05$ revealed by ANOVA analysis have been marked with an asterisk. As can be seen, both yeast strains showed fruity and balsamic as major series. Likewise, the OAVs for the 'floral' and 
'chemical' series were also higher with the S. bayanus strain than with the S. cerevisiae. In opposition, the OAVs for the fatty and empyreumatic series were higher with S. cerevisiae strain. Finally, neither of the yeast strains used was found to contribute to the spicy series.

On the other hand, in comparing the results obtained in the ageing experiments with the selected strains and the data for commercial wines, each OS was also subjected to an ANOVA. Only the fruity and balsamic series with the bayanus strain exhibited no significant differences with the commercial wines. All of the other series exhibited significantly lower OAVs than the commercial wines, particularly the floral, chemical and spicy series. The former series is mainly contributed to by terpenic compounds, and some authors (Zea et al., 1995; Cortes et al., 1998) have noted the ability of these "flor" yeasts to synthesise small amounts of these compounds, so the yeast strain used and cell autolysis in long time ageing (corresponding to the commercial wines), which may give rise to differences in their concentrations. Also, one should note that the duration of the experiments with the selected strains ( 9 months) may have been insufficient for the accumulation of terpenes, which could be reached with an ageing period of over 5 years, such as with the commercial wines used. Regarding the chemical and spicy series, the absence of 4-ethylguaiacol and eugenol may account for the differences observed. These compounds are slowly extracted from cask wood (Etievant, 1991; Aznar et al., 2001; Ferreira et al., 2001) and, therefore, they were present in the commercial wines aged in oak wood but absent in the wines aged in glass vessels.

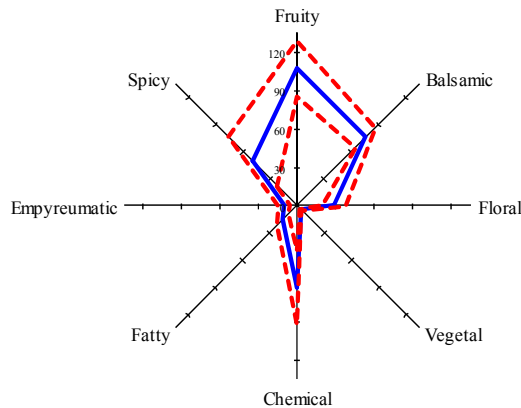

(a)

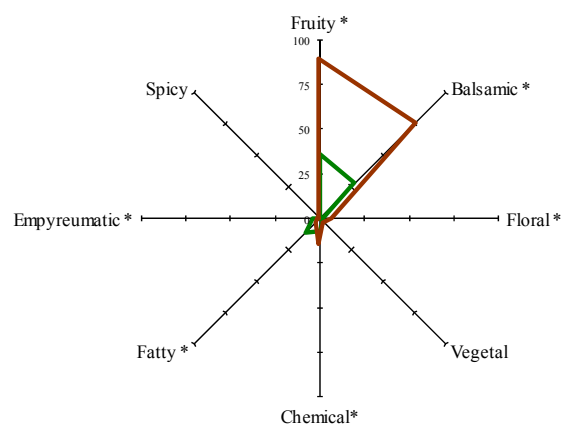

(b)

Fig. 4. (a) Aromatic profile of commercial wines:- means, - - - standard deviation. (b)

Aromatic profile of the wines aged with two flor yeasts: - cerevisiae strains and bayanus strains

On the whole, the results reveal that the main effects of the yeast strain used are exerted on the major OSs (fruity and balsamic). In this respect, the higher production of the bayanus strain in relation to the main compound contributors to these series confers characteristics similar to those of the commercial wines in a much shorter time ( 9 months versus 5 years).

On the other hand, contact with wood casks is necessary for the aroma profile of the wines obtained with selected strains to resemble that of commercial wines. In this sense, wine could be aged with selected strains of yeast in the wood casks themselves. However, maintaining the conditions required by the selected yeast cultures (mainly an appropriate temperature and the absence of contamination during the process) on an industrial scale is rather difficult. Therefore, it is reasonable to think that wine could be aged in two steps, 
firstly under controlled conditions (yeast and temperature) intended to achieve most of the sensory profile of the sherry wines, and secondly under less strictly controlled conditions, in wood casks. Taking into account the efficiency showed by S. bayanus, the overall duration of the two steps could be shorter than that of the traditional ageing process, which would result in decreased costs.

\subsection{Use of odorant series to estimate the relative contribution of the activity of "flor" yeasts and the extraction from wood}

The contribution of wood to the aroma of aged Fino wine has been clearly shown in earlier experiments carried out to shorten the biological ageing time (Cortes et al., 1999; Moyano et al., 2002).

As mentioned already, the OSs which included most of the compounds from the wood were the empyreumatic and spicy. The empyreumatic series has a higher $p$ and $\mathrm{R}^{2}$ values than the spicy series (see section 7.1). Nevertheless, the spicy series was significant at $p<0.01$, exhibiting a $R^{2}$ of 0.5617 and a slope of 13.4. According to Wonnacott \& Wonnacott (1995) and SilvaFerreira et al. (2003), a model can be assumed to fit experimental data well if it provides a correlation coefficient higher than $0.7\left(\mathrm{R}^{2}=0.4900\right)$. In addition, the spicy series includes eugenol (a compound extracted from wood and strong contributor in this series), in addition to the odorant compounds of interest present in the empyreumatic series. Therefore, the spicy series should better represent the contribution of wood to the biological ageing process.

Figure 5 shows the OAVs for the fruity series (indicator of the "flor" yeasts activity) versus those for the spicy series. The statistical program adjusted the data to a straight line obtaining a high correlation coefficient (0.7888) and a slope of 1.95 . The points within the line represent the sensory balance between the two OSs, whereas the zones outside it represent an imbalance in favour of the compounds related to the yeasts' activity (above) or those provided by the wood (below). In addition, the plot allows an estimate of the ageing time needed to obtain a determined quality (which has a direct impact on the marketing price of the wine), because the higher points on the line represent a higher degree of ageing.

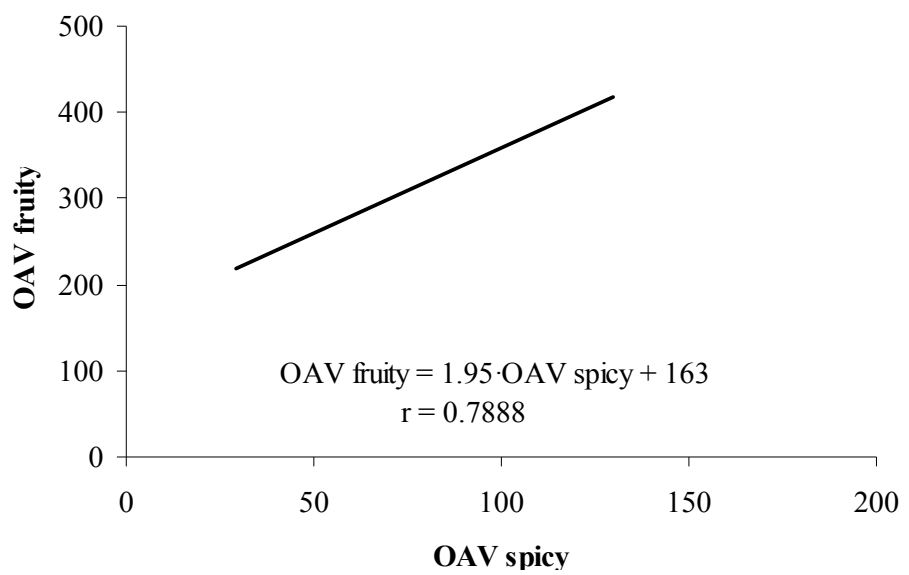

Fig. 5. Odorant Activity Values (OAVs) for the fruity series versus those of the spicy series in sherry-type wines during their biological ageing. 


\subsection{Odorant series as fingerprints for biological ageing in sherry wines}

In this study, the aroma compounds detected by Gas Chromatography Olfactometry (GC-O) and with $O A V>1$ in at least one of the wine samples were considered. The use of OSs allows one to not only identify those series that contribute to the aroma profile of a wine, but also to rank them in terms of their odorant capacity and obtain its aromatic fingerprint.

To determine and compare the aromatic fingerprint of Fino sherry wines aged for different periods, the OAVs for the compounds with similar olfactory features were classified into the eight OSs identified as those best representing the aroma of this type of wine. Figure 6 shows the aromatic fingerprint of the young wine $(0$ years $)$ and in those subjected to biological ageing for 2.5 and 6 years by arranging the mean values for each OS from high to low.

With the exception of the floral series and - to an extent - the fatty series, the results exhibit an increase in OAV with ageing time, and this is especially marked for the empyreumatic and fruity series. It can be seen that this pattern is preserved during the ageing time, except for the empyreumatic and vegetal series, as a result of the increased OAVs for sotolon and methionol respectively.
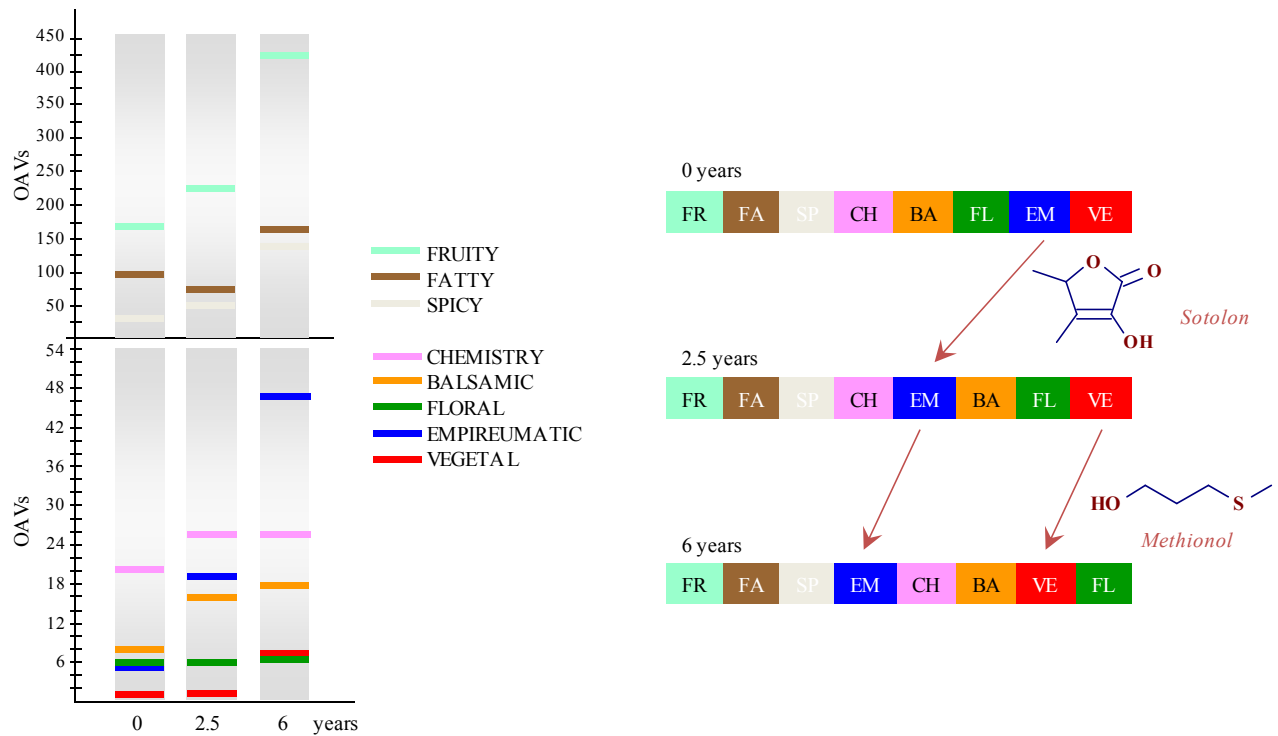

Fig. 6. The fingerprints of sherry wines during their biological ageing.

In conclusion, the aroma fingerprint for the oldest wine ("solera") can be quantitatively defined as fruity, fatty, spicy, empyreumatic, chemical, balsamic, vegetal and floral, in that order. A comparison of the OAVs for these series allows one to estimate the relative contribution of aroma compounds during the biological ageing of Fino sherry wines. In addition, and taking into account that the oldest wines are more valued by consumers, the aroma fingerprint can be advantageously used with a view to improving their sensorial quality. 


\section{Conclusion}

The use of OSs as analytical tool for the study of the ageing of sherry wines is very useful; however, some aspects if the grouping of the compounds in the OSs established by this study admit of some criticism. Accordingly, the addition of the compounds' OAVs to calculate a series cannot be interpreted as an arithmetical addition of odorant sensations. Moreover, the assignment of some compounds to a particular series - or several series - may be arguable. In any case, the proposed method is valid for comparing wines of the same type (very pale sherry wines in this work) because the OSs are always comprised by the same compounds. However, this method for aroma fraction study has the advantage that it strongly reduces the number of variables to be interpreted, preserving their relative importance according to the OAVs of the compounds assembled.

\section{References}

Arapitsas, P., Antonopoulos, A., Stefanou, E., \& Dourtoglou, VG. (2004). Artificial aging of wines using oak chips. Food Chemistry, Vol. 86, No. 4, (August, 2004), pp. (563-570), ISSN: 0308-8146.

Aznar, M., López, R., Cacho, J., \& Ferreira, V. (2001). Identification and quantification of impacts odorants of aged red wines from Rioja. GC-olfactometry, quantitative GCMS, and odor evaluation of HPLC fractions. Journal of Agricultural and. Food Chemistry, Vol. 49, No. 6, (June, 2001), pp. (2924-2929), ISNN: 0021-8561.

Baron, R., Mayen, M., Merida, J., \& Medina M (1997). Changes in Phenolic Compounds and Browning during Biological Aging of Sherry-Type Wine. Journal of Agricultural and Food Chemistry, Vol. 45, No. 5, (May, 1997), pp. (1682-1685), ISNN: 0021-8561.

Bayonove, C., Baumes, R., Crouzet, J., \& Gunata, Z. (2000). Aromas. In: Enología: Fundamentos científicos y tecnológicos, AMV, pp. (137-176), Mundi-Prensa, ISBN: 848476-074-X, Madrid.

Casas, J.F. (1985). Descripción resumida de la técnica enológica de los vinos de Jérez. In: III Jornadas universitarias sobre el Jerez, pp. (333-361), University of Cadiz press, ISBN: 84-600-4052-6, Cadiz.

Charles, M., Martin, B., Ginies, C., Etievant, P., Coste, G., \& Guichard, E. (2000). Potent aroma compounds of two red wine vinegars. Journal of Agricultural and Food Chemistry, Vol. 48, No. 1, (January, 2000), pp. (70-77), ISNN: 0021-8561.

Chaves, M., Zea, L., Moyano, L., \& Medina, M. (2007). Changes in color and odorant compounds during oxidative aging of Pedro Ximenez sweet wines. Journal of Agricultural and Food Chemistry, Vol. 55, No. 9, (May, 2007), pp. (3592-3598), ISNN: 0021-8561.

Cliff, M., Yuksel, D., Girard, B., \& King, M. (2002). Characterization of Canadian Ice wines by sensory and compositional analyses. American Journal of Enology and Viticulture, Vol. 53, No. 1, pp. (46-53), ISNN: 0002-9254.

Cortes M.B, Moreno J, Zea L, Moyano, L., \& Medina, M. (1998). Changes in aroma compounds of Sherry wines during their biological aging carried out by Saccharomyces cerevisiae strains bayanus and capensis. Journal of Agricultural and Food Chemistry, Vol. 46, No. 6, (June, 1998), pp. (2389-2394), ISNN: 0021-8561.

Cortes, M.B, Moreno, J., Zea, L., Moyano, L., \& Medina M. (1999). Response of the aroma fraction in Sherry wines subjected to accelerate biological aging. Journal of 
Agricultural and Food Chemistry, Vol. 47, No. 8, (August, 1999), pp. (3297-3302), ISNN: 0021-8561.

Domecq, B. (1989). Sherry: State of art on a very special fermentation product. In: Proceedings of the International Symposium on Yeasts, pp. (15-35), University of Leuven, Leuven.

Etievant, P. Wine. (1991). In: Volatile compounds in food and beverages; Maarse, H., pp. (486546), Zeist, ISBN: 0824783905, The Netherlands.

Ferreira, V., Aznar, M., Lopez, R., \& Cacho, J. (2001). Quantitative gas chromatographyolfactometry carried out at different dilutions of an extract. Key differences in the odor profiles of four high-quality Spanish aged red wines. Journal of Agricultural and Food Chemistry, Vol. 49, No. 10, (September, 2001), pp. (4818-4824), ISNN: 00218561.

Freitas, V., Ramalho, P., Azevedo, Z., \& Macedo, A. (1999). Identification of some volatile descriptors of the rock-rose-like aroma of fortified red wines from Douro demarcated region. Journal of Agricultural and Food Chemistry, Vol. 47, No. 10, (October, 1999), pp. (4327-4331), ISNN: 0021-8561.

Garcia-Maiquez, E. (1988). Les levures de voile dans l'elaboration des vins de Xerez. In: OIV Aplication a l'œnologie des progres recents en microbiologie et en fermentation, pp. (341351), OIV press, Paris.

Guijo, S., Millán, C., \& Ortega, J.M. (1986). Fermentative features of vinification and maturation yeasts isolated in the Montilla-Moriles region of southern Spain. Food Microbiology, Vol. 3, No. 2. (April, 1986), pp. (133-142), ISNN: 0740-0020.

Guth, H. (1997). Quantitation and sensory studies of character impact odorants of different white wine varieties. Journal of Agricultural and Food Chemistry, Vol. 45, No. 8, (August, 1997), pp. (3027-3032), ISNN: 0021-8561.

Kotseridis, Y., \& Baumes, R. (2000). Identification of impact odorants in Bordeaux red grapes juice, in the commercial yeast used for its fermentation, and in the produced wine. Journal of Agricultural and Food Chemistry, Vol. 48, No. 2, (February, 2000), pp. (400406), ISNN: 0021-8561.

Kreger-van Rij, N.J.W. (1984). The yeasts. A taxonomic study, (3rd Edition), Elsevier Science Publishers B.V, ISBN: 0-44480421-8, Amsterdam.

Kurtzman, C. P., \& Fell, J. W. (1998). The yeasts. A taxonomic study, (4th Edition). Elsevier Science Publishers B.V, ISBN: 0-44481312-8, Amsterdam.

Lambrechts, M.G., \& Pretorius, I.S. (2000). Yeast and its importance to wine aroma- A Review, South African Journal Enology and Viticulture, Vol. 21, No. 1, pp. (97-129). ISNN: 0253939X.

Lopez, R., Ferreira, V., Hernandez, P., \& Cacho, J. (1999). Identification of impact odorants of young red wines made with Merlot, Cabernet Sauvignon and Grenache grape varieties: a comparative study. Journal of the Science and Food Agriculture, Vol. 79, No. 11, (November, 1999), pp. (1461-1467), ISNN: 0021-8561.

Lopez, R., Ortin, N., Perez-Trujillo, J.P., Cacho, J., \& Ferreira, V. (2003). Impact odorants of different white wines from the Canary Islands. Journal of Agricultural and Food Chemistry, Vol. 51, No. 11, (May, 2003), pp. (3419-3425), ISNN: 0021-8561.

Martinez, E., Perez L., \& Benitez, T. (1997). Velum formation by flor yeasts isolated from sherry wine. American Journal of Enology and Viticulture, Vol. 48. No. 1, (January, 1997), pp. (160-168), ISNN: 0002-9254. 
Medina, M., Moreno, J., Merida, J., Mayen, M., Zea, L., \& Moyano, L. (2003). Sherry/Composition and Analysis, In: Encyclopaedia of Food Sciences and Nutrition, Trugo, L.; Finglas, P. \& Caballero, B., pp. (5257-5261), Academic Press, ISBN: 0-12227055-X, London.

Moreno, J., Millán, C., Ortega, J.M., \& Medina, M. (1991). Analytical differentiation of wine fermentations using pure and mixed yeast cultures. Journal of Industrial Microbiology, Vol. 7, No. 3, pp. (181-190), ISNN: 0169-4146.

Moreno, J.A., Zea, L., Moyano, L., \& Medina, M. (2005). Aroma compounds as markers of the changes in sherry wines subjected to biological ageing. Food Control, Vol. 16, No. 4, (April, 2005), pp. (333-338), ISNN: 0956-7135.

Moyano, L., Zea, L., Moreno, J., \& Medina, M. (2002). Analytical study of aromatic series in sherry wines subjected to biological ageing. Journal of Agricultural and Food Chemistry, Vol. 50, No. 25, (December, 2002), pp. (7356-7361), ISNN: 0021-8561.

Moyano, L., Zea, L., Villafuerte, L., \& Medina, M. (2009). Comparison of odor-active compounds in sherry wines processed from ecologically and conventionally grown Pedro Ximenez grapes. Journal of Agricultural and Food Chemistry, Vol. 57, No. 3, (February, 2009), pp. (968-973), ISNN: 0021-8561.

Moyano, L., Zea, L., Moreno, J.A., \& Medina, M. (2010). Evaluation of the active odorants in Amontillado sherry wines during the aging process. Journal of Agricultural and Food Chemistry, Vol. 58, No. 11, (June, 2010), pp. (6900-6904), ISNN: 0021-8561.

Noble, A.C., Arnold, R.A., Masuda, B.M., Pecore, J.O., Schmidt, J.O., \& Stern, P.M. (1984). Progress towards a standardized system of wine aroma terminology. American Journal of Enology and Viticulture, Vol. 35, No. 2, pp. (107-109), ISNN: 0002-9254.

Noble, A.C., Arnold, R.A., Buechsenstein, J., Leach, E.J., Schmidt, J.O., \& Stern, P.M. (1987). Modification of a standardized system of wine aroma terminology. American Journal of Enology and Viticulture, Vol. 38, No. 2, pp. (143-146), ISNN: 0002-9254.

Rocha, S.M., Rodrigues, F., Coutinho, P., Delgadillo, I., \& Coimbra, M.A. (2004). Volatile composition of Baga red wine: Assessment of the identification of the would-be impact odorants. Analytica Chimica Acta, Vol. 513, No. 1, (June, 2004), pp. (257-262), ISSN: 0003-2670.

Ruiz, M.J., Zea, L., Moyano, L., \& Medina, M. (2010). Aroma active compounds during the drying of grapes cv. Pedro Ximenez destined to the production of sweet Sherry wine. European Food Research and Technology, Vol. 230, No. 3, (December, 2009), pp. (429-435), ISNN: 1438-2377.

Silva-Ferreira, A.C., Oliveira, C., Hogg, T., \& Guedes de Pinho, P. (2003). Relationship between potenciometric measurements, sensorial analysis, and some substances responsible for aroma degradation of white wines. Journal of Agricultural and Food Chemistry, Vol. 51, No. 10, (July, 2003), pp. (4668-4672), ISNN: 0021-8561.

Singleton, V. (1995). Maturation of wines and spirits: comparison, facts, and hypotheses. American Journal of Enology and Viticulture, Vol. 46, pp. (98-115), ISNN: 0002-9254.

Wonnacott, T.H., \& Wonnacott, R.J. (1995). Statistique, (4eme edition), Economica, ISBN: 27178-2072-8, Paris.

Zea, L., Moreno, J., Ortega, J.M., \& Medina, M. (1995). Content of free terpenic compounds in cells and musts during vinification with three Sacharomyces cerevisae races. Journal of Agricultural and Food Chemistry, Vol. 43, No. 4, pp. (1110-1114), ISNN: 0021-8561. 
Zea, L., Cortes, M.B., Moreno, J., \& Medina, M. (1996). Vinos finos. Crianza. Investigación y Ciencia, Vol. 236, pp. (78-81), ISSN: 9770210136004.

Zea, L., Moyano, L., Moreno, J., Cortes, B., \& Medina, M. (2001). Discrimination of the aroma fraction of Sherry wines obtained by oxidative and biological Ageing. Food Chemistry, Vol. 75, No. 1, (October, 2001), pp. (79-84), ISSN: 0308-8146.

Zea, L., Moyano, L., Moreno, J.A., \& Medina, M. (2007). Aroma series as fingerprints for biological ageing in fino sherry-type wines. Journal of the Science of Food and Agriculture, Vol. 87, No. 12, (September, 2007), pp. (2319-2326), ISNN: 0021-8561.

Zea, L., Moyano, L., \& Medina, M. (2008). Odorant active compounds in Amontillado wines obtained by combination of two consecutive ageing processes. European Food Research and Technology, Vol. 227, No. 6, (October, 2008), pp. (1687-1692), ISNN: 1438-2377.

Zea, L., Moyano, L., \& Medina, M. (2010). Changes in aroma profile of sherry wines during the oxidative ageing. International Journal of Food Science and Technology, Vol. 45, No. 11, (November, 2010), pp. (2425-2432), ISNN: 0950-5423. 


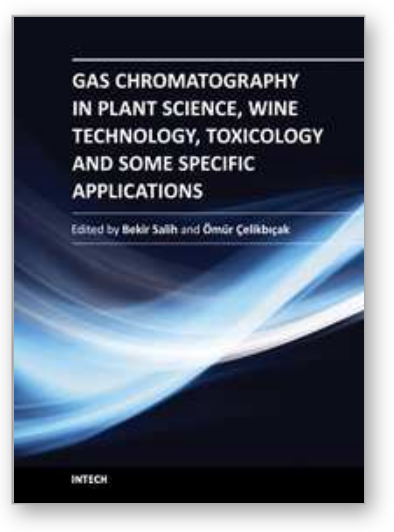

\author{
Gas Chromatography in Plant Science, Wine Technology, \\ Toxicology and Some Specific Applications \\ Edited by Dr. Bekir Salih
}

ISBN 978-953-51-0127-7

Hard cover, 346 pages

Publisher InTech

Published online 29, February, 2012

Published in print edition February, 2012

The aim of this book is to describe the fundamental aspects and details of certain gas chromatography applications in Plant Science, Wine technology, Toxicology and the other specific disciplines that are currently being researched. The very best gas chromatography experts have been chosen as authors in each area. The individual chapter has been written to be self-contained so that readers may peruse particular topics but can pursue the other chapters in the each section to gain more insight about different gas chromatography applications in the same research field. This book will surely be useful to gas chromatography users who are desirous of perfecting themselves in one of the important branch of analytical chemistry.

\title{
How to reference
}

In order to correctly reference this scholarly work, feel free to copy and paste the following:

Luis Zea, María J. Ruiz and Lourdes Moyano (2012). Using Odorant Series as an Analytical Tool for the Study of the Biological Ageing of Sherry Wines, Gas Chromatography in Plant Science, Wine Technology, Toxicology and Some Specific Applications, Dr. Bekir Salih (Ed.), ISBN: 978-953-51-0127-7, InTech, Available from: http://www.intechopen.com/books/gas-chromatography-in-plant-science-wine-technology-toxicology-andsome-specific-applications/using-odorant-series-as-an-analytical-tool-for-the-study-of-the-biological-ageing-ofsherry-wines

\section{INTECH}

open science | open minds

\author{
InTech Europe \\ University Campus STeP Ri \\ Slavka Krautzeka 83/A \\ 51000 Rijeka, Croatia \\ Phone: +385 (51) 770447 \\ Fax: +385 (51) 686166 \\ www.intechopen.com
}

\author{
InTech China \\ Unit 405, Office Block, Hotel Equatorial Shanghai \\ No.65, Yan An Road (West), Shanghai, 200040, China \\ 中国上海市延安西路65号上海国际贵都大饭店办公楼405单元 \\ Phone: +86-21-62489820 \\ Fax: +86-21-62489821
}


(C) 2012 The Author(s). Licensee IntechOpen. This is an open access article distributed under the terms of the Creative Commons Attribution 3.0 License, which permits unrestricted use, distribution, and reproduction in any medium, provided the original work is properly cited. 